Lexis Vol. XLV (1) 2021: 287-316

\title{
Testimonio y autobiografía: hacia una noción de narrativas testimoniales del yo en el cine y la literatura de posdictadura argentina
}

\author{
Carolina C. Bartalini \\ https://orcid.org/0000-0002-1749-4436 \\ UNTREF - UNAJ - CONICET \\ cbartalini@untref.edu.ar
}

\section{RESUMEN}

A lo largo de los años que siguieron a la reapertura democrática, en el cine y la literatura, se han producido diferentes maneras de figurar las experiencias de las víctimas de la última dictadura cívico-militar argentina (1976-1983) en cercano vínculo con los acontecimientos de cada coyuntura. Entre el discurso testimonial y los procedimientos de la autobiografía, a partir del siglo XXI se abre un nuevo género multimedial en proliferación: las narrativas testimoniales del yo. En ellas se configuran formas estéticopolíticas peculiares e innovadoras de abordar las experiencias de memoria de la segunda generación del genocidio de Estado, las exploraciones del cine, la literatura y la fotografía de la generación de las hijas e hijos de personas desparecidas.

Palabras clave: testimonio, autobiografía, posdictadura, memoria 
Testimony and Autobiography: Towards a Concept of Narrative Testimonials of the Self in Film and Literature of Argentina Postdictatorship

\begin{abstract}
Throughout the years that followed the democratic reopening, there have been different ways of figuring out the experiences of the victims of the last Argentine civil-military dictatorship (1976-1983) in cinema and literature. Between the testimonial discourse and the autobiography procedures, a new proliferating multimedia genre opens up from the 21st century: the testimonial narratives of the self. In them, peculiar and innovative aesthetic-political forms of addressing the experiences of memory of the second generation of the state genocide are configured, the explorations of cinema, literature and the photography of the generation of the daughters and sons of disappeared people.
\end{abstract}

Keywords: testimony, autobiography, post-dictatorship, memory

\title{
1. Breve memoria
}

La noción de testimonio del yo involucra dos zonas discursivas, la autobiografía y el género testimonial, mediante las cuales los relatos sobre el genocidio en Argentina ${ }^{1}$ han abordado la cuestión y desempeñado un rol decisivo - junto con los reclamos públicos de los organismos de derechos humanos- en la configuración de imágenes sociales sobre diversos aspectos del plan sistemático de represión y desaparición de la última dictadura cívico-militar (1976-1983). Desde el arco literario y cinematográfico, los géneros

\footnotetext{
1 Sigo el uso del término "genocidio" de los estudios de Daniel Feierstein que analizan la trama de la última dictadura militar desde un abordaje más amplio que el dispositivo planificado y sistemático de represión y desaparición de personas. Feierstein plantea que, así como sucedió en el genocidio nazi y en los regímenes fascistas europeos, en las dictaduras del Cono Sur se puso en práctica el exterminio de grupos sociales, políticos, raciales y de género con el objetivo mayor de desintegrar los lazos sociales y los derechos civiles que en Argentina se habían institucionalizado durante el primer peronismo, para reorganizarlos en pos de la economía supranacional del modelo neoliberal. Véase Feierstein 2007 y 2009.
} 
que se abocaron al tema fueron la narrativa testimonial (llamada a partir de la poética de Rodolfo Walsh, no-ficción), el documental histórico y/o político, y la ficción a secas — novelas y películas de época, cuentos, relatos, e incluso la autobiografía como una zona residual del mercado literario-.

Es cierto que también hubo narrativas y poéticas contemporáneas al período dictatorial que, de formas más o menos directas, abordaron distintas aristas de la represión del Estado tanto desde la denuncia de los exiliados y los dispositivos creados para difundir las atrocidades del totalitarismo en el exterior, ${ }^{2}$ como también en el cine testimonial documental ${ }^{3} y$ en el orden de la imaginación

2 La creación de la revista Controversia en el año 1979 por parte de exiliados políticos residentes en México, como Héctor Schmucler, Juan Carlos Pontantiero, Nicolás Casullo, José Aricó, Oscar Terán y Jorge Tula, fue un espacio importante para la difusión y la reflexión sobre la dictadura argentina y el Plan Cóndor ejecutado en América Latina así como las publicaciones y boletines que circulaban en y desde París, organizadas por los militantes de Montoneros, ERP, militantes trotskistas e independientes - el CAIS (Centre Argentin d'Information et Solidarité)—, y las de organismos de derechos humanos formados previamente en Argentina - la CADHU (Commission Argentine des Droits de l'Homme) y el CO.SO.FAM (Commissión de Solidarité des Parents des Prisonniers, Disparus et Tués en Argentine) (véase Franco 2008)—, por señalar tan solo algunos casos. Asimismo, también fue significativa la circulación internacional del periódico autogestionado por exiliados desde París, Sin censura. Periódico de información internacional para América Latina, cuyo comité de dirección estaba integrado por Julio Cortázar, Osvaldo Soriano, Carlos Gabetta, Oscar Martínez Zemboarain, entre otras figuras destacadas del periodismo y la literatura argentina, que se publicó entre noviembre de 1979 y julio de 1980 en seis números (véase Martínez Zemborain y Castro 2014).

3 En el cine hubo varios casos de películas documentales que incorporaron algunas entrevistas testimoniales y otras entrevistas o discursos denunciativos durante la dictadura desde el exilio: el grupo de Cine de la Base exiliados en Perú luego de la detención y desaparición de Raymundo Gleyzer, su fundador, realizaron en 1977 Las tres AAA son las tres armas, un documental basado en la Carta Abierta de Rodolfo Walsh. Luego, algunos de ellos filmaron en Italia Persistir es vencer (1978), en torno a las entrevistas a Luis Mattini y Enrique Gorriarán Merlo, dirigentes del P.R.T - E.R.P. Jorge Cedrón en Francia realizó en colaboración con Juan Gelman Resistir (1978), una entrevista a Mario Firmenich, y Tango (1979). Gerardo Vallejo en España produce Reflexiones de un salvaje (1978), una forma oblicua de contar el exilio desde la recuperación de la herencia cultural familiar. En 1979 Humberto Ríos —quien fuera previamente profesor de Gleyzer- produce en México Esta voz... entre muchas, la primera película documental que muestra las voces de sobrevivientes y madres de detenidos-desaparecidos en el exilio, entre ellos la temprana denuncia de Laura Bonaparte. Esta tradición fue forjada en la narrativa argentina, como es sabido, por Rodolfo Walsh desde Operación Masacre (1957), ¿Quién mató a Rosendo? 
ficcional. ${ }^{4}$ Desde la resistencia interna, y clandestina, la Carta abierta a la Junta Militar (1977) que Rodolfo Walsh hizo circular al cumplirse el primer año del golpe -y que resultó su último acto de política y de vida-resulta un documento ineludible que retrata en presencia los alcances macro y micro políticos del plan sistemático de represión y desaparición de los intereses financieros trasnacionales; la planificación de la miseria.

El género testimonial — que de acuerdo con el trabajo historiográfico de Annette Wieviorka define al siglo XX, como "la era del testigo" $— 5$ cobró centralidad en los círculos académicos norteamericanos, europeos y latinoamericanos a finales de la década

(1969) y Caso Satanowsky (1973); mientras que en el cine desde los proyectos documentalistas del Grupo Cine Liberación organizado por Fernando Solanas, Octavio Getino, Gerardo Vallejo, Enrique Juárez (La hora de los hornos, 1968, Ya es tiempo de violencia, 1969, Argentina, mayo de 1969: Los caminos de la liberación, 1969); así como desde el Cine de la Base, fundado por Raymundo Gleyzer en torno a la película Los traidores (1973). En esta línea, la palabra testimonial aflora del trabajo del director o del autor-investigador que ofrece un espacio textual para entregarle la voz al otro - que aflora, incluso, desde el marco de la ficción-, los desposeídos, los sobrevivientes, aquellos que exponen la violencia de los aparatos de disciplinamiento del poder totalitario del Estado en sus cuerpos. Sobre este tema, ver Peña y Vallina 2000; Mestman 2008; Aprea 2015; Prividera 2014.

4 En el "área” de la ficción, podemos distinguir entre algunos libros escritos y publicados en Argentina bajo el gobierno dictatorial que, de acuerdo con Carlos Gamerro (2015) hacen uso de la elipsis, el desplazamiento y la alegoría para eludir la censura, como Respiración artificial de Ricardo Piglia (1980); y aquellos otros publicados fuera del país, en el exilio de sus autores, como El beso de la mujer araña (1976), Pubis angelical (1979), Maldición eterna a quien lea estas páginas (1980) de Manuel Puig, Nadie, nada, nunca (1980) de Juan José Saer, el poema “Cadáveres” publicado en Alambres (1987) de Néstor Perlongher, Cuarteles de invierno (1982) de Osvaldo Soriano, Cuerpo a cuerpo (1979) de David Viñas, y las novelas escritas en dictadura pero publicadas después como Los pichy-cyegos de Rodolfo Fogwill (1983) o La larga noche de Francisco Sanctis (1984) de Humberto Constantini, entre otros casos.

5 Wieviorka se refiere a la importancia fundamental de los testigos de los campos de exterminio del nazismo para dar cuenta de su existencia, dada la destrucción de las pruebas por parte de los nazis. En este sentido, esta observación es muy pertinente para el caso argentino ya que los testimonios de los sobrevivientes han sido los pilares del juicio a las Juntas Militares de 1985, así como para la reconstrucción del accionar de las fuerzas represivas del Estado en los juicios de Lesa Humanidad que actualmente se siguen llevando a cabo, puesto que acá también se destruyen las pruebas. Los centros clandestinos fueron reutilizados con funciones varias o destruidos (hasta que en 2004 se establece la intención de recuperarlos como "espacios de memoria") y los militares han mantenido el más atroz silencio sobre la información que ocultan —dónde están 
del ochenta a partir de tres episodios. El primero, la publicación en 1983 (en la colección de Testimonios de Casa de las Américas ${ }^{6}$ ) por parte de la antropóloga venezolana Elizabeth Burgos Debray del volumen testimonial Me llamo Rigoberta Menchú y así me nació la conciencia, que relata la vida y los padecimientos de Rigoberta Menchú, luchadora por los derechos del pueblo maya quiché. El libro despertó rápidamente una controversia en torno a la autoría que se potenció al momento de la entrega del Premio Nobel de la Paz a Rigoberta Menchú en 1992, así como una serie de debates acerca de la representatividad del testimonio en primera persona para dar cuenta de una comunidad, e incluso sobre la fiabilidad y veracidad histórica de estos discursos (véase Beverley 1992, 2004).

En segundo lugar, la publicación en 1986 de Los bundidos y los salvados, última obra testimonial de Primo Levi en relación a su experiencia en el campo de exterminio nazi periférico de Auschwitz, Monowice, y una profunda reflexión sobre el totalitarismo y el estatuto del testimonio para la memoria social. Por último, en abril de 1990 se produce un ya célebre debate entre historiadores, sociólogos y escritores convocados por el historiador israelí Saul Friedländer en torno a los límites y posibilidades de la representación para dar cuenta del horror del Holocausto, que se editó luego en forma de libro en 1995 - En torno a los límites de la representación. El nazismo y la solución final ([1995] 2007) — con intervenciones

los cuerpos de los desaparecidos, dónde están los chicos ilegítimamente apropiados, qué hicieron, quiénes más estuvieron involucrados.

6 Cabe destacar que la categoría "Testimonio" en el certamen literario de Casa de las Américas se inicia en 1970. Es en ese momento, a finales de la década del sesenta, cuando comienza a utilizarse el término testimonio para mencionar obras literarias latinoamericanas que confluyen hacia "una narración del largo de una novela o nouvelle, dicha en primera persona por un narrador que también es el protagonista o testigo real de los eventos que cuenta" (Beverley 1991: 2). Esto sucede en íntima relación, de acuerdo con Victoria García (2012), con las publicaciones Biografía de un cimarrón del cubano Miguel Barnet (1966), La guerrilla tupamara de María Esther Giglio (primera obra ganadora de la categoría Testimonio de Casa de las Américas, en 1970), La noche de Tlatelolco: testimonios de historia oral de la mexicana Elena Poniatowska, Si me permiten bablar... de la brasileña Moema Viezzer (1974). A esta serie, habría que agregar la tercera y cuarta edición de Operación Masacre de Rodolfo Walsh en 1969 y 1972, así como la publicación de ¿Quién mató a Rosendo? en 1969 y Caso Satanowsky en 1973. 
de Hayden White, Carlo Ginzburg, Perry Anderson, Jürgen Habermas, Martin Jay, Vincent Pecora, Dominick LaCapra y Eric Santner, entre otros. El eje de la discusión, nuevamente, es el estatuto del lenguaje para presentar y re-presentar lo que Friedländer llamó "un suceso límite", es decir, un acontecimiento impensado, inimaginable, aquello que ha alterado las bases "para la continuidad de las condiciones de vida en la historia” (Friedländer 2007: 23).?

Mientras tanto, durante la década del ochenta en Argentina predominó en la escena pública y mediática la proliferación de testimonios de sobrevivientes de los campos clandestinos de detención y los reclamos de los familiares de detenidos-desaparecidos que permitieron a la justicia condenar a los militares responsables. ${ }^{8}$ Esta primera escena que se cifra en el informe de la Comisión Nacional sobre la Desaparición de Personas, editado en el volumen

\begin{abstract}
7 El debate se organizó para pensar una cuestión propiamente discursiva: la relación entre enunciado y enunciación, es decir, los problemas y potencialidades de la lengua para dar cuenta de la experiencia límite. En este sentido se concluye hacia los vínculos entre el género testimonial, la historia y los procedimientos de representación. Hayden White, por su parte, focaliza en la cuestión del tono, la voz propia para narrar un evento límite, un suceso extremo con legitimidad ética, en contra del revisionismo y el negacionismo. Plantea, en contra de las ideas de Carlo Ginzburg — que expresan la necesidad de buscar en el testimonio los datos factuales, que recuperen la "historia"-, una zona que se concentre en el modo de representación, la búsqueda de una voz adecuada para representar acontecimientos únicos de la era moderna. Esta elección inevitable, tanto para el relato histórico como para el literario, “determina la especificidad de las diversas interpretaciones” (White en Friedländer 2007: 23). LaCapra, por su parte, descree de las técnicas convencionales y considera que nos son suficientes para representar sucesos límites que desafían los lindes de lo imaginario, tal como fue la administración de la muerte en el nazismo. Afirma que la configuración de una voz particular, un modo particular, es decir, un estilo, debe asociarse a cierta actitud empática como elemento afectivo de la comprensión [los resaltados me pertenecen]. Luego, en Escribir la historia, escribir el trauma ([2001] 2005) LaCapra continuará esta línea señalando una cuestión central a la que atender en los estudios sociales: la presencia de una voz, la construcción de una voz en el acto de testimoniar, es decir, de configurar experiencia y sujeto de la experiencia que permita el acercamiento empático con el otro.
\end{abstract}

8 Otros episodios testimoniales que se suman a los relatos de sobrevivientes en la televisión durante los primeros años del alfonsinismo - fenómeno al que Claudia Feld (2002) llamó el "show del horror"- son la temprana publicación del libro testimonial Recuerdo de la muerte (1984) de Miguel Bonasso; la edición de La escuelita, un volumen testimonial de Alicia Partnoy sobre el centro clandestino de Bahía Blanca; Botín de Guerra, testimonios de abuelas que buscan a sus nietos apropiados, compilado por Julio 
de amplia circulación Nunca Más ([1985] 2006), involucró, por un lado, el agenciamiento público de las voces antes silenciadas, y por el otro, en su contracara, la victimización de los detenidos-desaparecidos despolitizando sus idearios y causas que los convocaron a la militancia y la lucha armada en los setenta. El sintagma de la década, como es sabido, fue la teoría de los dos demonios que, si bien ponía en incorrecta relación de igualdad dos violencias profundamente diferentes y asimétricas - la del Estado y la de los grupos insurgentes- posibilitó, en tiempos todavía muy impregnados por el terror y el poder de las fuerzas armadas sobre la todavía frágil democracia, el despertar de la sociedad al orden de lo siniestro silen-

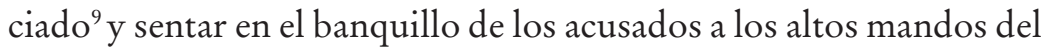
genocidio de Estado.

Esta profusión testimonial no aparecerá en la escena cinematográfica hasta el final de la década (aunque sí se la puso en foco en las proyecciones televisivas - sin audio- y entrevistas a víctimas y familiares en los resúmenes diarios del Juicio a las Juntas por los noticieros de canales argentinos). A comienzos de la corta década del ochenta ${ }^{10}$ prevaleció, en cambio, la fórmula de ficción

Nosiglia (1985); José, la reconstrucción intermedial que realiza Matilde Herrera sobre la vida de su hijo José Beláustegui (1987); entre otros.

9 La idea de una sociedad dormida que "despierta al horror", se observa en los mecanismos metafóricos que pone en marcha la película ganadora del premio Oscar La bistoria oficial (Luis Puenzo y Aída Bortnik 1985) a través de una serie de escenas de "despertares" visuales y discursivos de las mujeres (la protagonista, la amiga sobreviviente y exiliada que retorna al país, la niña apropiada, la abuela de Plaza de Mayo que encuentra a la familia apropiadora). Sobre este tema, y el trabajo con la infancia como símbolo del estado social, véase Bartalini 2017.

10 La década del ochenta, en términos artísticos y políticos, puede pensarse desde la re-apertura democrática de 1983 hasta el fin de la presidencia de Raúl Alfonsín, con el adelanto de las elecciones y la anticipación de la entrega del mando al recientemente electo presidente Carlos Saúl Menem el 8 de julio de 1989. En ambos sentidos, político y cultural, los ochenta se desmarcan de la "larga década del setenta" y se postulan como un período de mucha intensidad no concordante con el tiempo cronológico. En la escena de la música, por poner otro ejemplo, las muertes precoces de Luca Prodan (22 de diciembre de 1987), Miguel Abuelo (26 de marzo de 1988) y Federico Moura (21 de diciembre de 1988), los dos últimos a causa del VIH, marcan un hiato entre la cultura del rock de la década previa, la coyuntura propia de los ochenta — que en Argentina implicó dos zonas muy marcadas de rebeldía contra institucional, el punk rock y el tecno-pop- y 
cristalizada en La bistoria oficial (1985), que expone en las grandes pantallas el robo de los hijos de militantes secuestrados y desaparecidos como núcleo del horror del plan sistemático del terrorismo de Estado. ${ }^{11}$ El cine documental tuvo poco protagonismo durante la década del ochenta. Dos películas son centrales, ambas de Carlos Echeverría: Cuarentena (1983), sobre el exilio y regreso de Osvaldo Bayer a la Argentina, ${ }^{12}$ y Juan, como si nada bubiera sucedido (1987) sobre la desaparición de Juan Herman en Bariloche y los pactos de silencio de la sociedad y los militares responsables. ${ }^{13}$

el comienzo de los noventa, una década marcada por otras inflexiones, especialmente la internacionalización de la música, los mega festivales y, a la vez, las resistencias del circuito del under.

11 Otros filmes que tematizaron de una u otra forma los años de plomo fueron: Camila (1984) de María Luisa Bemberg, Hay unos tipos abajo (1985) de Rafael Filippelli, Andrés Di Tella y Julio Karp, El amor es una mujer gorda (1988) de Alejandro Agresti, Sur (1988) de Fernando Solanas, entre otros.

12 Carlos Echeverría filmó a Osvaldo Bayer en Alemania desde que la idea de regresar al país, luego de ocho años de exilio, comenzó a ser un motor de vida para el autor de Los vengadores de la Patagonia trágica (1972-1974). La película acompaña a Bayer en Berlín en sus deliberaciones junto con otros exiliados, sobre la posibilidad y el peligro del retorno todavía en dictadura. Bayer y Echeverría llegan a la Argentina, como en un antecedente no risueño de un reality show, y la cámara también lo acompaña el día de las elecciones que se muestran desde la redacción de Clarín, el diario donde Bayer había trabajado antes del exilio. Cuarentena ofrece un notable trabajo de archivo instalándose en dos temas no abordados antes ni después: el retorno del exilio en tiempo real -el temor y el silencio propio de los ochenta, como epílogo dictatorial一; y la reapertura democrática mostrada, además, desde la perspectiva del periodismo y el acto eleccionario-. Asimismo, propone una poética visual que ya anticipa el siguiente largometraje documental de Carlos Echeverría, Juan, como si nada bubiera sucedido (1987), y muchos de los procedimientos estéticos —así como la investigación documental como gesto estético y político- que utilizan Albertina Carri en Los rubios y Nicolás Prividera en $M$ (2007). Más allá de esto, Cuarentena plantea una dimensión vitalista del cine que permite no solamente averiguar puntos oscuros de la historia reciente a partir de la investigación documental, que apunta tanto al plano de lo social como al subjetivo de sus personajes o investigados, sino también producir vida a partir del cine, tal como sucedió con Osvaldo Bayer quien efectivamente pudo retornar a la Argentina en diciembre de 1983 gracias al financiamiento que el proyecto de Echeverría había logrado de parte de la Televisión alemana. (Fuente: conversación personal con Carlos Echeverría).

13 Aunque la difusión de ambas películas fue muy limitada en el país, es importante resaltar su profunda contundencia y las líneas de continuidad que se pueden observar entre ellas y el cine de Albertina Carri y Nicolás Prividera, en cuanto a los procedimientos de búsqueda como motor del filme pero a la vez el descubrimiento de la verdad gracias a ese proceso, los cruces de lo íntimo con lo social y la mirada ensayística del 
Durante la década del noventa se produce un desplazamiento en el foco discursivo hacia las memorias de militancia, la recuperación de aquellas zonas de las que en los años previos no se había podido hablar en la escena pública. Las figuras de los militantes son exaltadas, sus idearios y trayectos revolucionarios se recuperan y aparece la imagen de una "gesta heroica" que se recuperaba como "frustrada" por el dispositivo represivo de la dictadura militar. Se publica la monumental trilogía testimonial La voluntad (1997-1998) de Martín Caparrós y Eduardo Anguita, donde se habilita la enunciación de los sobrevivientes que recuperan sus militancias y relatan episodios de intimidad y comunidad en los años setenta, así como testimonios sobre sus secuestros y cautiverios que permiten una mirada más amplia y compleja sobre el tema. En el cine, el punto de inflexión es el documental de David Blaustein Cazadores de utopias sobre el PET-ERP (1996) y el estreno de Montoneros, una historia en 1998 de Andrés Di Tella (aunque rodado desde principios de la década). Asimismo, la ficción irrumpe nuevamente con una película de puesta en abismo, que trabaja desde la producción de un filme de búsqueda y regreso del exilio, Un muro de silencio (1993) de Lita Stantic. Luego Garage Olimpo (1999) de Marco Bechís, pone el foco en el horror de las torturas y la administración de la muerte en los campos clandestinos de detención en un giro hacia el despojamiento y la crudeza que también explorará Adrián Caetano tiempo después en Crónica de una fuga (2006), ambos claros exponentes del Nuevo cine argentino.

La literatura de la década del noventa, a la inversa de lo que había sucedido en los años anteriores, se vuelca hacia la ficción, dejándole el espacio de lo político-documental al cine (Aguilar 2006). Las obras que trabajan el pasado dictatorial lo hacen desde diferentes abordajes: la narrativa novelada que incorpora la trama histórica a la intimidad familiar como sucede en El Dock (1994) de Matilde Sánchez, El fin de la historia (1996) de Liliana Heker, El carapálida

tono, además de los desdoblamientos y mediaciones brechtianas, especialmente trabajadas en Juan, como si nada bubiera sucedido. 
(1997) de Luis Chitarroni; así como también elaborando la inversión y el extrañamiento, como lo hace Martín Kohan en Dos veces junio (2002).${ }^{14}$ Otra zona importante de esta década es la que corresponde al ensayo que elude la presencia del yo, como es el caso de la publicación de Pilar Calveiro, exdetenida y luego exiliada en México, quien compone una brillante tesis análisis sociológico sobre la relación entre sociedad y poder concentracionario en Poder y desaparición. Los campos de concentración en la Argentina (1998). ${ }^{15}$

Alrededor de 2001 irrumpen en la escena pública las exploraciones artísticas de los hijos de desaparecidos en simultáneo con otras que también siguen escribiendo sobre ese pasado de la infancia y/o primera juventud ${ }^{16}$, desde un nuevo modo de mostrar la política ya no como transparencia sino como opacidad (Aguilar 2006, Amado 2009); es decir, exponiendo formas no directas que abandonan la idea de "pueblo" como agente de la revolución en los setenta, o la manifestación del “despertar a la verdad” en los ochenta, para pasar a su omisión, la manifestación de su degradación o su otredad, como sucede en las revisiones del género documental-testimonial que realizan Albertina Carri y Nicolás Prividera.

14 Otras novelas de esta escena son: Las islas (1998) de Carlos Gamerro, A veinte años luz (1998) de Elsa Osorio, Hay unos tipos abajo (1998) de Antonio Dal Masetto, El terrorista (1998) de Daniel Guebel, Ni muerto has perdido tu nombre (2002) de Luis Gusmán, El secreto y las voces (2002) de Carlos Gamerro.

15 Este libro, junto con la re-edición de los ensayos que el sociólogo Emilio De Ípola había redactado a fines de la década del setenta en el exilio sobre su prisión política durante los primeros años de la dictadura militar en La bemba. Acerca del rumor carcelario ([1978] 2005), configuran una zona nueva de la tradición del ensayo de "interpretación nacional” en torno a los límites de la violencia y el totalitarismo en nuestro país.

16 Pienso en novelas como El origen de la tristeza (2004) de Pablo Ramos, Ciencias morales (2007) de Martín Kohan, Historia del pelo (2010) de Alan Pauls, Bajo este sol tremendo (2009) de Carlos Busqued, relatos de Los Lemmings (2002) de Fabián Casas, de La mafia rusa (2008) de Daniel Link, El principio del terror (2010) de Diego Fischerman; así como películas como Vidas privadas (2001) de Fito Páez, Kamchatka (2002) de Marcelo Piñeyro, Cautiva (2005) de Gastón Birabén, Hermanas (2005) de Julia Solomoff, Crónica de una fuga (2006) de Adrián Caetano, Infancia clandestina (2011) de Benjamin Ávila, todas ellas recuperan diversas aristas de ese pasado de la memoria fuertemente impregnadas del dispositivo que Ludmer señala como realidadficción. 
Desde la aparición de Los rubios, primer documental de Albertina Carri - y antes, desde el mediometraje de tesis realizado entre México y Argentina por María Inés Roque, Papá Iván (2000)—, se han producido diversas y cautivantes formas artísticas de transformar las memorias en experiencias que ponen en primer plano no solo el tiempo de la memoria personal, sino también las tensiones en torno a los vínculos entre vivencia, experiencia e historia de la nación en exploraciones estético-políticas subjetivantes. Me refiero a ciertas películas, literaturas y prácticas performáticas que configuran zonas de inmanencia entre géneros y formas de abordar el pasado recientes desde las aristas del cuerpo, el deseo y el archivo. Entre ellas vienen conformando un género multimedial en proliferación que avanza en nuevas y novedosas voces, procedimientos y temáticas siempre pisando la línea de fuego entre historia personal/familiar, la historia nacional y la Historia (con mayúscula), o el mainstream de la memoria.

Hablo de producciones cinematográficas como (b) Historias cotidianas (2000) y El (im)posible olvido (2016) de Andrés Habegger, $M$ (2007) de Nicolás Prividera, Encontrando a Víctor (2004) y Tiempo suspendido (2015) de Natalia Bruschtein, El padre (2015) de Mariana Arruti, La guardería (2016) de Virginia Croatto; literaturas de exploración como la narrativa y las puestas performáticas de Félix Bruzzone (76, Los topos, 2008), Campo de mayo (2019); Campo de Mayo, conferencia performática (Bruzzone y Arias, 2016) y Cuarto intermedio, guia práctica para juicios de lesa bumanidad (de Félix Bruzzone y Mónica Zwaig, 2018), Soy un bravo piloto de la nueva China (2011) de Ernesto Semán, Diario de una princesa montonera $-110 \%$ verdad (2012) de Mariana Eva Pérez, ¿Quién te creés que sos? (2012) de Ángela Urondo Raboy, Cómo enterrar a un padre desaparecido (2012) de Sebastián Hacher, Una muchacha muy bella (2013) de Julián López, El sexo de las piedras (2014) y Un veneno de sí (2016) de Fernando Araldi Oesterheld, Aparecida (2015) de Marta Dillon; así como también desde el dispositivo fotográfico y visual en Arqueología de la ausencia (1999-2001) de Lucila 
Quieto y desde el género dramático, el teatro documental de Lola Arias en Mi vida después (2009).

Por supuesto, también se produjeron paralelamente notables películas documentales del orden más tradicional que convergieron hacia lo que Josefina Ludmer llama "el tiempo de la memoria": Raymundo (2003) de Virna Molina y Ernesto Ardito, Trelew. La fuga que fue masacre (2004) de Mariana Arruti, ${ }^{17}$ Paco Urondo, la palabra justa (2005) de Daniel Desaloms, El futuro es nuestro (2014) de Virna Molina y Ernesto Ardito. Asimismo, otros documentales que, ya avanzada la segunda década del dos mil, también exploraron la sutil frontera de la vida familiar con la historia nacional, como las marcas del exilio en SC Recortes de prensa (2014) de Oriana Castro y Nicolás Martínez Zemborain, o la palabra de los perpetradores en tensión con la investigación histórica como sucede en 70 y pico $(2016)^{18}$ de Mariano Corbacho y Juan Pablo Díaz. ${ }^{19}$

Sin embargo, la escena fundante que da cuenta del sintagma narrativas testimoniales del yo que propongo en este trabajo se retrotrae a un tiempo anterior. Me refiero a dos momentos textuales que desdibujan los límites entre los géneros tradicionales: el vitalismo disruptivo de la poesía junto con la denuncia social y la intimidad de las cartas personales junto con la interpelación revul-

\footnotetext{
17 Mariana Arruti filmará años después El padre (2016) una exploración performática que podríamos incluir también en la serie, con nuevas inflexiones.

18 Esta película habilita, y requiere, una lectura específica, ya que es el primer episodio en el cine nacional que se enuncia desde la mirada del nieto de un cómplice de la dictadura militar, el exdecano interventor de la Facultad de Arquitectura y Urbanismo de la UBA, Héctor Mario Corbacho, acusado de conformar las listas negras y entregar a los 130 estudiantes de la FADU desaparecidos. Asimismo, es un notable documental histórico sobre la escena política y militante en las universidades y el "espíritu” juvenil de los setenta. Da cuenta también de una nueva escena en formación, la de las voces de los hijos, hijas y familiares de genocidas que repudian públicamente el accionar de sus progenitores y familiares.

19 Para el análisis fílmico de esta década, habría que tener en cuenta también la prolífica realización de películas y series documentales del Canal Encuentro durante la gestión de María Rosenfeldt a partir de su fundación en el año 2006. Entre ellos una de las temáticas principales fueron los derechos humanos, documentales como Acá estamos, historias de nietos que recuperaron su identidad, Nietos, identidad y memoria, 99,99\% La ciencia de las abuelas, Madres de plaza de mayo, la historia, Padres de la Plaza, etcétera.
} 
siva de la intervención política. El momento inicial refiere al poema Carta abierta - publicado en 1967- que Francisco Paco Urondo le dedica a su mujer y sus hijos, a quienes incluye como interlocutores imaginarios de sus versos sobre lo inefable de la ausencia y el futuro incierto: "queridos hijitos, su papá poco sabe de ustedes y sufre por esto [...]”. ${ }^{20} \mathrm{El}$ segundo, la serie epistolar del último año de vida de Rodolfo Walsh sobre el asesinato de su hija, Victoria Walsh: la Carta a Vicky, la Carta a los amigos (1976); y su último estertor en la Carta abierta a la Junta Militar (1977).

En estos textos, de radical impregnación político-vital, aparece la figura de un yo que enuncia la historia social desde su propia corporalidad atravesada por la violencia más íntima: los autores se vuelven testigos de sí, la literatura es cuerpo. Ya no están parados en la figura de tercera persona - propia del relato testimonial y de noficción de aquella época- que da la voz “del letrado” (Nofal 2002) a los que no la tienen, bajo las figuras del intelectual comprometido, o el militante-intelectual que tanto Walsh como Urondo desempeñaron política y literariamente.

Por el contrario, en estas escenas se produce un desplazamiento de la voz: la trama violenta del presente la atraviesa. ${ }^{21}$ La enunciación cambia hacia la bio-testimonialidad, una escena fundacional que da cuenta de las inflexiones de la voz testimonial sobre la propia vivencia-ausencia, que siempre es también del otro.

20 Este poema fue publicado en el libro Del otro lado, 1960-1965, y obtuvo mención del honor del Premio Casa de las Américas.

${ }^{21}$ La literatura de denuncia de Rodolfo Walsh ya ha sido citada. En el caso de Francisco Paco Urondo me refiero especialmente a La patria fusilada (1973), un libro testimonial producto de las entrevistas que el poeta entabló con los sobrevivientes de la masacre de Trelew en la prisión de Villa Devoto (cuyas cintas fueron casualmente "salvadas" por la amnistía a los presos políticos del presidente Héctor José Cámpora). Este libro recupera una zona testimonial recientemente consolidada en la época, cuyo origen, lo dijimos, fue Operación Masacre. Urondo transcribe las entrevistas a los sobrevivientes de los fusilamientos a los militantes de Montoneros y el Ejército Revolucionario del Pueblo que se habían escapado del penal de Rawson y que luego se rindieron en el aeropuerto sin llegar a escapar a Chile como era el plan de fuga inicial. La difusión de este hecho aceleró el tránsito que el gobierno de facto había prometido hacia las elecciones libres, que le darían la victoria a Héctor Cámpora en marzo de 1973. 
En estos textos de dos de los escritores más potentes de la prosa y la poesía del siglo pasado, ambos detenidos y desaparecidos por el aparato represor y genocida de la dictadura cívico-militar, se pueden percibir los ecos futuros de las respuestas performáticas de la generación de los hijos a partir de ciertos mecanismos de afiliación procedimental que las obras de esta serie producen en relación con las materialidades con las que trabajan: los objetos afectivos que son para los hijos las cartas que sus padres y madres les escribieron antes de que fueran secuestrados o asesinados, ${ }^{22}$ donde el cuerpo se deja oír sin mediaciones en la temporalidad del testimonio de sí. Este escenario enunciativo señalado posibilita una lectura en términos de contemporaneidad generacional, ${ }^{23}$ un espacio de diálogo que se cristalizaría, en términos poéticos, en la figura de la prosopopeya, trabajada por Paul de Man ([1984] 1991) para dar cuenta de las inflexiones del género autobiográfico.

\section{Colecciones afectivas en la escena autobiográfica}

El montaje de voces y materialidades compositivas con las que los escritores y cineastas de la generación del 2001 organizan sus relatos es un rasgo central de sus experiencias de memorias. En el cine ha predominado el trabajo con el testimonio y las fotografías, como puestas en abismo de la misma condición de creación audiovisual —

22 Por supuesto, me refiero a "padres" e "hijos" como nociones generacionales que no necesariamente incluyen rasgos filiativos directos, sino más bien líneas de encuentro entre dos zonas de enunciación temporalmente sucesivas, aunque violentamente distanciadas.

23 Giorgio Agamben ([2006] 2014) proyecta, en relación al sujeto y su tiempo, que "la contemporaneidad es, pues, una relación singular con el propio tiempo, que se adhiere a este y, a la vez, toma su distancia; más exactamente, es esa relación con el tiempo que se adhiere a éste a través de un desfase y un anacronismo" (18, el subrayado es del autor). Lo contemporáneo se propone como un adjetivo absoluto y no relacionante, como un atributo del sujeto que "mantiene la mirada fija en su tiempo, para percibir, no sus luces, sino su oscuridad” (19). La relación que se expone no es inter-subjetiva sino inter-temporal. Todo tiempo tiene dos caras que conviven, aunque habitualmente una se esconda en la otra. El poeta contemporáneo es, para Agamben, quien tiene la capacidad —el don o el coraje- para percibir lo que los demás no pueden observar: la simultaneidad, el absoluto del tiempo en un momento histórico que se vislumbra eventual. 
tal vez el punto central que permite identificar el trabajo formal que se pone en juego en este género-, mientras que en los relatos literarios $^{24}$ lo que aparece con mayor insistencia son las tradiciones de la literatura del yo: cartas, diarios íntimos, autobiografías, poemas, crónicas y diversas instancias de cruces intermediales. Estas materialidades pueden ser pensadas como objetos auráticos dado que, siguiendo la terminología de Walter Benjamin, son elementos que invocan un efecto de percepción, no de producción; "la manifestación irrepetible de una lejanía" (Benjamin 1972a-b). Son objetos de la memoria afectiva de los autores y realizadores que se muestran y se vuelven a imaginar - en el caso de las fotos y las voces testimoniales - y a escribir —en el de las cartas y los poemas-, cuya exhibición desafía los pactos de lectura del realismo documental en tanto que, en principio, funcionan como aperturas en el aquí y ahora al lector/espectador con el enunciado y la función autoral.

Pero, a la vez, la exhibición de estos objetos resignifica las demandas históricas de los organismos de derechos humanos recuperando el valor cultural, en términos de Benjamin, que tienen las imágenes fotográficas. Un valor mágico, que asocia representación con cuerpo, que hace de la imagen fotográfica una invocación. Ben-

24 Como señalé previamente, trabajo con una idea amplia de literatura en tanto letra, es decir, relatos textuales impresos en forma de libro u otros soportes digitales de difusión y lectura. Como he analizado (véase Bartalini 2018a), los géneros de los textos del corpus se retuercen en derivas del testimonio, la no-ficción, la crónica, la novela epistolar, el diario íntimo, la biografía y la autobiografía (cada una de ellas merecería análisis específicos en cuanto a sus estatutos, tradiciones y rupturas, incluso la reflexión sobre cómo son leídos, dentro o fuera de "lo literario"). Sin embargo, en este punto es preciso valerse de un término que nos permita establecer un pacto común de comunicación. Así, la palabra "literatura" se irá tornando a lo largo del trabajo hacia la noción de "prácticas narrativas", y ésta hacia el concepto de "testimonios del yo", una categoría más amplia que incluye diversos lenguajes y formatos que no se presentan necesariamente bajo la forma predominantemente "narrativa” en cuanto a las tipologías de la lingüística textual de orientación comunicativa (Brinker 1988) que distingue entre tipos básicos descriptivos, narrativos, explicativos y argumentativos dada la función textual, los criterios contextuales y estructurales del texto en cuestión (véase Ciapuscio 1994). Sin embargo, incluyen el rasgo central que William Labov observó con respecto a las "narrativas de experiencia personal”, la aparición de un segmento evaluativo en el que el narrador revela su actitud con respecto a su relato (véase Labov y Waletzky 1967, Labov 1972). 
jamin analiza que el valor cultural de la imagen fotográfica "tiene su último refugio en el culto al recuerdo de los seres queridos, lejanos o desaparecidos" (1972a: 31), y que nunca termina de ceder sin resistencias al valor exhibitivo propio de la racionalidad moderna. El valor exhibitivo, afirma Benjamin, "comienza a reprimir en toda la línea al valor cultural. Pero éste no cede sin resistencia” (1972a: 31), y re-aparece disimuladamente en lo que Roland Barthes ([1980] 1989) llama el punctum de la fotografía: el azar, la irrepetible presencia de lo imprevisto. En otras palabras, el trabajo con las fotografías y con las cartas mantiene activo el sentido mágico, luminoso, y a la vez desolador, de la presencia de la ausencia, tal como sucede al operar con materiales afectivos que se vuelven fetiches de un vínculo aún vivo desde su tacto, su manipulación, su resguardo y su exhibición.

Los objetos auráticos permiten hablar a los ausentes a través de ellos, mediante la figura que Paul de Man observa en la textura de Essays upon Epitaphs de Wordworth, la prosopopeya, que aúna en el presente las voces de los que no pueden hablar con quienes los invocan en su discurso. Para de Man ([1984] 1991), este tropo establece una tensión entre lo "literal” y lo "figural” en tanto que permite movernos dialécticamente entre la invocación — “dar voz a aquello que no habla, de dar vida a lo muerto dotándolo de una máscara textual”, como reformula Sylvia Molloy (1996: 11)— y el agenciamiento discursivo - "la modalidad en que los sobrevivientes hablan en persona” (de Man: 9)—. ${ }^{25}$ Marcelo Topuzian (2003) señala que "las figuras no solo permiten dar vida a aquello que no la tiene (por ejemplo, un sujeto 'autobiográfico') sino que también instalan la muerte en el mundo de los vivos” (2003: 270). En este sentido, la autobiografía se mueve —al igual que el género testimonial— en

\footnotetext{
25 Marcelo Topuzian (2003) observa que la crítica ha leído equivocadamente el análisis que de Man realiza con respecto a este tropo. Si bien es cierto, como nos alerta Topuzian, que los textos de este autor se orientan hacia la generalización teórica dentro de los estándares modales del conocimiento académico, en "La autobiografía como desfiguración" Paul de Man trabaja con Wordworth no como ejemplo sino como materialidad analítica. Es allí donde se interesa por los modos en que esta figura de sustitución tropológica opera para dar cuenta de la imposibilidad de otorgarle una voz a quien no está presente, aunque figuralmente este desplazamiento se realice.
} 
una tensión irresoluble: mientras que se pretende dar cuenta de sí mismo a través de un lenguaje figural —metafórico, prosopopéyico, metonímico - se cae en la paradoja de su imposibilidad: “el lenguaje, como tropo, produce siempre privación, es siempre despojador" (de Man en Topuzian: 270).

Es sabido que la autobiografía, como el testimonio, es una puesta en escena, una decisión estratégica, que supone los mismos procedimientos que la ficción. Este es el principal problema con el que se encuentran quienes tratan de definir el género desde criterios textuales como, por ejemplo, la textualidad tropológica que postulan las teorías narratológicas (véase Martínez y Scheffel 2011) que termina agotándose en la misma irreductibilidad textual para dar cuenta de las complejidades de lo autobiográfico. Lo mismo sucede con la pragmática textual, que observa al género desde la dimensión de los pactos de lectura que se proponen - y aceptarían por el lector- en la línea de los estudios de Philippe Lejeune (1975), los cuales tampoco terminan de "asir" la porosidad de los relatos autobiográficos, pero señalan, al menos, sus problemas. Lejeune insiste en que la autobiografía es un tipo particular de ficción y que su yo y su verdad son realidades tanto creadas como (re)descubiertas. En El pacto autobiográfico, Lejeune retoma el problema de la distinción de la narratología entre discurso factual y ficcional y plantea el papel central del nombre propio como "tema profundo de la autobiografía” (1975: 73), resaltando que su verdadero locus no se ubica en el enunciado sino en el de la enunciación —al "acto autobiográfico”- La cuestión del nombre se vuelve central puesto que sería la signatura que vehiculiza una endeble identidad factual que se desdobla entre las figuras del autor, el narrador y el protagonista, cuya relación debe ser postulada y activada por el lector, de modo que en esta línea: "la historia de la autobiografía sería entonces, más que nada, la de sus modos de lectura” (Lejeune 1975: 87).

La poética de la autobiografía está íntimamente asociada a la del testimonio a pesar de que sus atmósferas de producción y lectura hayan sido marcadamente distintas a lo largo de la historia. Mientras que, como comentamos, la autobiografía surge y se asocia a la 
intimidad apacible del mundo burgués que da origen a la noción de lo privado, paradójicamente asociado a la letra pública; el testimonio - especialmente en las inflexiones del género que se dieron en América Latina (como señalan Alejandra Oberti y Claudia Bacci [2014]) - se vincula directamente con el relato de carácter denunciativo de las violencias de los poderes institucionales que han atravesado la historia comunitaria e íntima de nuestro cuerpo continental. Sin embargo, desde esta compleja porosidad que se activa en la enunciación de un yo que atraviesa y distingue ambos géneros (aunque en el testimonio a través del acto ético-político-enunciativo de "dar la palabra a los que no están”), surge otra dimensión que los impregna y convoca a una serie de nuevos, y sutiles, problemas: ¿qué sucede cuándo el relato de la vida - lo bio- da cuenta también de lo colectivo, pero ya no como representatividad sino como impregnación vital? En ambos casos —en la autobiografía y el testimonio- el trabajo con el lenguaje se construye a partir de sus huecos, de sus imposibilidades. No renunciar a este aspecto, no pretender suturarlo, nos permitirá escuchar los abismos de la voz, lo cóncavo del lenguaje que hace experiencia en su tránsito.

\section{El testimonio como performatividad de la experiencia}

El testimonio es un género poroso, anclado al afecto y a los efectos del lenguaje sobre el mundo y sobre el mismo enunciador. Así, el testimonio, y el género que lo reúne en las múltiples inflexiones que van desde su primera función social relativa al ámbito judicial, como en las enunciaciones de rigor sociológico, histórico o artístico, presenta dos planos de significación. Dar testimonio es una experiencia de lenguaje y como tal involucra enunciado y enunciación, un plano semiótico y otro semántico (Benveniste [1974] 1999). ${ }^{26}$ Dar testimonio es también una acción, es la toma de la

\footnotetext{
26 Sigo las líneas de Emile Benveniste en Problemas de lingüística general (1999 [1974]) en torno a la definición de la enunciación como un proceso de apropiación de la lengua llevada a cabo por el "locutor", quien en el hecho de discurso asume el aparato formal de la lengua e implanta al otro delante de este. En consecuencia, el enunciado es el pro-
} 
palabra, un posicionamiento, un gesto. En este sentido, pasado y presente se hibridan en el tiempo del discurso testimonial, así como repetición y diferencia. ${ }^{27}$ El testimonio es un acto performativo de lenguaje que produce experiencia en su misma enunciación. De aquí la idea de testimonios del yo, una zona entre diversos planos de sentidos que trabaja incluso con procedimientos de extrañamiento y puesta en abismo de cada una de sus partes: testimonios montados sobre pluralidad de voces testimoniantes, escenas autobiográficas mínimas sobre la construcción de una enunciación de vida.

Las definiciones sociológicas del testimonio ya señalan las presencia reconocible y potente del yo como marca del género: un acto de discurso en primera persona, en un determinado contexto social, sobre hechos relevantes (para uno, para el colectivo) con una determinada voz, en una situación de discurso naturalmente dialógica (se habla ante alguien y contra alguien) e intrínsecamente polifónica (Bacci y Oberti 2014). Rossana Nofal (2002) observa que los estudios de la corriente crítica de los estudios subalternos (Jara y Vidal 1986, Beverley 1992) han abordado la cuestión testimonial desde la idea de "representatividad" de los testimonios latinoamericanos, en los que funcionaría la enunciación y la lectura metonímica, es decir, un caso por el todo (como sucedió en el debate con respecto

ducto de este movimiento dialógico de alocución. Por otro lado, me refiero al orden de lo semiótico como "el modo de significación que es propio del signo lingüístico y que lo constituye como unidad”, mientras que lo semántico, en cambio, refiere al modo de significación del discurso, en tanto producción de significados y sentidos inevitablemente sociales (Benveniste en Agamben 2015: 74). Me interesan estas nociones debido a que nos permiten pensar los dos espacios instaurados por la enunciación testimonial, en tanto que lo semiótico plantea reconocimiento y lo semántico requiere de la comprensión. En la línea que vengo sosteniendo esto se observa en el pacto de lectura testimonial que implica dos facultades distintas: la de percibir la identidad y, por lo tanto, la alteridad; y la de percibir el significado de una enunciación nueva, única e irrepetible.

27 Tal como analiza Paul Ricoeur (2004), al testimonio se le exige la ipseidad pero a la vez está situado en un terreno presente que inevitablemente involucra desplazamientos —vitales, ideológicos, retóricos, políticos-con respecto a la palabra antes pronunciada. Así como sucede con el recuerdo, el testimonio es discontinuo y motivado. Así como sucede con la memoria, el testimonio es fragmentario, poroso, repetible y diferente en cada enunciación, y, por supuesto, así como participa de la asignación de roles identitarios, provoca un acoplamiento subjetivo. 
al caso de Rigoberta Menchú y la comunidad maya quiché). Nofal llama "testimonio clásico" a los relatos pronunciados por un sujeto “analfabeto" 28 a quien otro sujeto con acceso al discurso público -bajo las figuras del “intelectual comprometido”, el sociólogo, el etnógrafo, el lingüista, el documentalista, el periodista, el escritor-, habilita su palabra para que dé cuenta de sus vivencias personales y comunitarias. Por tanto, en este sentido, el testimonio como género es leído desde la función del testis, aquel que cuenta en primera persona lo que le sucedió a un tercero. Asimismo, Nofal (2002) plantea que el estudio del género adquiere especiales características cuando aparece la función autoral, que ella llama "testimonio letrado" (por corresponder a "autores de literatura” que abren una zona testimonial en una obra más extensa no necesariamente sostenida en este género), puesto que se produce un desplazamiento de la pragmática testimonial que elimina la mediación de la palabra de uno dicha y recortada, seleccionada por otro y montada en la palabra ajena.

Así, como señalé con respecto a la serie epistolar del yo de Rodolfo Walsh, entre el testimonio clásico y el testimonio letrado aparecen diferencias sustanciales que responden principalmente a la pragmática, puesto que, aunque en ambos la primera persona enuncia, en el segundo grupo se produce una mixtura que plantea las mediaciones al interior de sí.

Sostenida por un cuerpo, analiza Ana Amado, "la palabra testimonial se tiende como un puente hacia el universo de signos" (2009: 127). La palabra testimonial, en tanto performatividad de la experiencia, configura y expone la sonoridad del cuerpo en su voz. Claudia Bacci analiza que el testimonio es, en primer lugar, un "dispositivo de escucha" más que un "dispositivo de preguntas": “ese espacio que se abre $-\mathrm{y}$ el silencio que lo rodea-, donde los tiempos y las voces se dan la mano, metamorfosea un nosotros momentáneo” (2015: 536). De ese modo, Alejandra Oberti

\footnotetext{
28 Sigo en este punto la argumentación de Rossana Nofal (2002), aunque matizaría la noción de "analfabeto" y propondría la idea de sujetos sin acceso a la voz pública, que es en definitiva lo que sucede con los sujetos de enunciación del testimonio clásico antes de que se ponga en práctica la mediación institucional/autoral.
} 
y Claudia Bacci observan que "una clave para pensar su estatuto reside en comprenderlo como un acto a través del cual se muestra la actualidad del pasado en el presente. Así, el testimonio le aporta el gesto fundamental porque deja ese resto, esa sobre vivencia en la posibilidad — que es a la vez la imposibilidad-de hablar" (Bacci y Oberti 2014: 7). En este sentido, el testimonio implica una decisión estratégica del sujeto, a la vez que un modo recursivo y reiterativo de presentar y re-presentar lo inefable. De acuerdo con Paul Ricoeur (2004), así como la identidad personal es mutable, también lo es el testimonio que está destinado a la repetición, a la vez que a su diferencia, y se mueve entre los polos de lo que cambia y lo que permanece.

En esta tensión, Giorgio Agamben observa que el testimonio presenta inevitablemente una "laguna”, un “exceso" en términos de Dominick LaCapra (2005): lo no-decible y lo imposible de testimoniar porque o bien no se ha vivido - como experiencia extrema de la muerte, lo inenarrable-, o bien porque no hay palabras que puedan dar cuenta de la vivencia personal que se pretende contar. ${ }^{29}$

En los casos de los relatos de las hijas e hijos que se vienen produciendo entre 2001 a la actualidad, la laguna del lenguaje testimonial se actualiza en ese entre narrar y no poder narrar, pero ya no desde la experiencia ajena, sino desde la propia enunciación; es decir, entre la legitimidad de la voz y las posibilidades — siempre tensas y complejas - de presentar al lector/espectador una experiencia que le resulte además de reconocible —en términos de la identidad semiótica-, posible de comprender (en el sentido semántico que Benveniste plantea en torno a la alocución). LaCapra ([2001] 2005) llama a este gesto "potencialidad empática del testimonio", considerando la empatía como "un elemento afectivo de la

29 Este es uno de los puntos centrales de la argumentación de Beatriz Sarlo en Tiempo Pasado (2005) en torno a los límites del testimonio como discurso fiable para la Historia y los estudios sociológicos. Esta lectura parte de un problema ontológico del género testimonial, pero lo ubica en un corpus cuyo enunciado testimonial no es la experiencia extrema de la desaparición desde el yo de los padres, sino la vivencia de su desaparición desde el yo de los hijos. Una experiencia diferente, totalmente habilitada, en principio, por la filiación y, luego, por la enunciación testimonial específica que ellos producen. 
comprensión” (119) que permitiría una relación transferencial con el pasado, exponiendo al yo de la autoría —aun también al lector/ espectador - al compromiso ético y afectivo de una vivencia revisada, vuelta a considerar.

En este sentido, tanto Dominick LaCapra como Joan Scott ([1991] 2001) plantean que el acto testimonial involucra un hecho de lenguaje que constituye experiencia de sí. LaCapra lo analiza desde el poder de revitalización de la propia historia que sucede durante la enunciación testimonial. Scott focaliza en la potencia subjetivante del relato de sí, en la actualización de la propia vida a partir del lenguaje. Siguiendo a Teresa de Lauretis (1984), Scott postula una redefinición de la noción de experiencia que apunta al agenciamiento discursivo y político que permita la contra-asignación de roles a través de los cuales uno se ubica o es ubicado en las relaciones materiales, económicas e interpersonales en un estado de sociedad. Para Scott "no son los individuos los que tienen la experiencia, sino los sujetos los que son constituidos por medio de la experiencia" (Scott 2001: 49). la experiencia no es entonces algo que los individuos “tengan", sino algo que producen y con esta producción se constituyen en tanto sujetos políticos. ${ }^{30} \mathrm{El}$ testimonio sería en principio el relato de la vivencia transformada en experiencia, de ahí su primera contradicción: la necesidad de repetición y su imposibilidad de repetirse.

En esa zona de imposibilidades que se figura en el problema de la lengua radica su segunda contradicción: el testimonio muestra la imposibilidad de testimoniar. No existe testigo integral, lo que

30 El testimonio no solo existe en su propia realización como acto de discurso, y de memoria, sino que también es utilizado en distintos ámbitos de la vida social para producir determinadas acciones y atribuirles a las palabras citadas ciertos efectos de sentido, tanto en el ámbito legal — donde el testimonio cobra una fuerza sustancial en la realización de acciones que modifican el mundo de manera concreta- como en los diferentes espacios de la construcción del conocimiento histórico, el análisis político y social, o bien el arte. La palabra testimonial se ha vuelto en las últimas dos décadas, de hecho, un notorio y prolífico dispositivo en las producciones artísticas que exceden el ámbito del documental testimonial tradicional, ingresando en los discursos estético-políticos como citas, materiales, hibridaciones, relaciones todas ellas de desdiferenciación de las nociones de autonomía y campos culturales propias del siglo pasado (véase Bartalini 2018b). 
queda es la experiencia del testimonio, el problema de su re-presentación y la figuración de su voz: ¿cómo narrar ese exceso inefable?, ¿quién puede testimoniar, quién quiere testimoniar, quién debe hacerlo? Para que la experiencia pueda cuestionar las identidades asignadas - no afirmarlas - hay que indagar en las configuraciones discursivas que subjetivizan y objetivan (Scott 2001). El estatuto de la experiencia y del testimonio es el lenguaje, y de este modo ambos disputan la legitimidad de la voz, de los significados y sus sentidos sociales.

La experiencia en el arte invoca estas mismas problemáticas pero sobre expuestas: si la cuestión de la experiencia y del testimonio ha sido el centro de los mayores debates de la historia y la sociología del siglo XX en cuanto a su potencialidad y posibilidad de narrar el horror de las situaciones de trauma individual y colectivo, e incluso y especialmente sobre su operatividad en un paradigma funcionalista que pone en primer plano la referencialidad, en el arte la experiencia se torna indiscernible de su forma y se pregunta especialmente por la voz.

En síntesis, la lucha por restituir el habla del objeto inanimado (la figura de la autobiografía), o del ausente (la figura del testimonio) a través de figuras de representación conduce al límite inefable (la figura del lenguaje) que al mismo tiempo que dice, calla; que al hablar enuncia su imposibilidad de hacerlo. Así vista, la autobiografía como género expresaría más que la vida "previa" de su "referente", un a priori simulado por el discurso, el sujeto que la enuncia, el problema de la enunciación y todos los sentidos de lo que no es posible decir, como sucede también en el género testimonial, aunque con un dispositivo que necesita afirmar el yo para existir como tal.

Si la autobiografía pone en primer plano al sujeto, en este gesto también da cuenta de cierta primacía ontológica de su condición, considerando la existencia del individuo como previa al lenguaje. En este sentido, se plantea un mecanismo que da cuenta del efecto de realidad de los géneros biográficos, ubicando al lector como evaluador de la "veracidad" de los hechos relatados. O bien, de modo 
inverso, es el lector quien, al leer la autobiografía, crea - a partir de la autoficción de la autoría- el estatuto de existencia del sujeto en cuestión.

Por el contrario, en el género testimonial este pacto se vuelve imprescindible para su efectividad discursiva. En otras palabras, si el testimonio afirma lo real y la autobiografía la vida, es decir la imaginación, el dispositivo testimonial del yo se mueve entre esas zonas, siempre pantanosas, que son la imaginación de lo real: el cuerpo, el discurso. Como ha escrito Roland Barthes: “es quizá por el hecho de que me encanta (o me ensombrece) saber que la cosa de otro tiempo tocó realmente con sus radiaciones inmediatas (sus luminancias) la superficie que a su vez toca hoy mi mirada” ([1980] 1989: 127). La relación entre el material y el sujeto se vuelve táctil, muestra siempre lo que está, y más que nada lo que ya no: establece un vínculo físico, una comunidad de cuerpos y de deseos aun desde la ausencia, aun desde el recuerdo.

\section{Referencias bibliográficas}

Agamben, Giorgio

[2000] 2010 Lo que queda de Auschwitz. El archivo y el testigo. Homo Sacer III. Trad., A. Cuspinera. Barcelona: Pre-textos.

Agamben, Giorgio

[2006] 2014 “Qué es lo contemporáneo?”. En Desnudez. Trad., M. Ruvituso y M. T. D’Mesa. Buenos Aires: Adriana Hidalgo, 17-29.

Aguilar, Gonzalo

2006 Otros mundos. Un ensayo sobre el nuevo cine argentino. Buenos Aires: Santiago Arcos.

Amado, Ana

2009 La imagen justa. Cine argentino y politica (1980-2007). Buenos Aires: Colihue.

Andermann, Jens

2015 Nuevo cine argentino. Trad., F. Rodríguez. Buenos Aires: Paidós. 
Aprea, Gustavo

2015 Documental, testimonios y memorias. Miradas sobre el pasado militante. Buenos Aires: Manantial.

BACCI, Claudia

2015 “Numeralia: ¿Cuántas voces guarda un testimonio?”. Constelaciones. 7, 528-536.

Bacci, Claudia y Alejandra Oberti

2014 "Sobre el testimonio: una introducción". Clepsidra. Revista Interdisciplinaria de Estudios sobre Memoria: Dossier "Testimonios, debates y desafíos desde América Latina”. 1, 6-13.

BARTALINI, Carolina

2017 "Imágenes de infancias en el cine de posdictadura. De Los rubios a La historia oficial". En XIII Jornadas Nacionales de Historias de las Mujeres / VIII Congreso Iberoamericano de Estudios de Género, Facultad de Filosofía y Letras, Facultad de Ciencias Sociales-UBA, Universidad Nacional de Quilmes.

BARTALINI, Carolina

2018a "Experiencias de memoria, memorias de experiencias. Prácticas testimoniales del yo contemporáneas en el cine y la literatura argentina”. Tesis de Maestría. Universidad Nacional de Tres de Febrero.

BARTALIni, Carolina

2018b "Tradiciones y rupturas entre 2001. Una reflexión en torno a las tensiones del testimonio como performatividad estéticopolítica en Los rubios de Albertina Carri”. En Construir sobre los escombros. Politica y cultura en la Argentina post-crisis 2001. Comp., Julián Delgado y Mauricio Schuttenberg. Florencio Varela: Editorial UNAJ, 37-54.

BARTHEs, Roland

[1980] 1989 La cámara lúcida. Nota sobre la fotografía . Trad. y Pról., J. Sala-Sanahuja. Barcelona: Paidós.

BENJAMIN, Walter

[1931] "Pequeña historia de la fotografía”. En Discursos interrumpidos 1972a I. Filosofía del arte y de la historia. Trad., y Pról., J. Aguirre. Madrid: Taurus, 61-86. 
BENJAMIN, Walter

[1936] "La obra de arte en la época de su reproductibilidad técnica".

1972b En Discursos interrumpidos I. Filosofía del arte y de la historia. Trad. y Pról., J. Aguirre. Madrid: Taurus, 15-60.

Benveniste, Émile

[1974] 1999 Problemas de lingüistica general II. Trad., Juan Almela. México: Siglo XXI.

BeVERLEY, John

1992 "Introducción”. En Lavoz del otro: Testimonio, subalternidad $y$ verdad narrativa. Eds., John Beverley y Hugo Achugar. Lima-Berkeley: Latinoamericana editores, 17-32.

BeVERLey, John

2004 “NNuestra Rigoberta? Autoridad cultural y poder de gestión subalterno". En Subalternidad y representación. Debates en teoría cultural. Trad., M. Beiza y S. Villalobos-Ruminott. Madrid: Iberoamericana, 103-126.

BRINKER, Klaus

1988 El análisis lingüistico del texto. Trad., G. Ciapuscio. Documento de cátedra, FFyL, UBA. [Linguistiche Textanalyse. Eine Einführung in Grundbegriffe. Berlin: Erich Schmidt].

Burgos Debray, Elisabet

1983 Me llamo Rigoberta Menchú. La Habana: Casa de las Américas.

Calveiro, Pilar

[1998] 2014 Poder y desaparición. Los campos de concentración en Argentina. Buenos Aires: Colihue.

Ciapuscio, Guiomar

1994 Tipos textuales. Buenos Aires: FFyL, UBA.

Comisión Nacional sobre la Desaparición de Personas

[1984] 2006 Nunca más: Informe de la Comisión Nacional sobre la Desaparición de Personas. Buenos Aires: Eudeba.

De ÍPOLA, Emilio

[1978] 2005 "La bemba". En La bemba. Acerca del rumor carcelario y otros ensayos. Buenos Aires: Siglo XXI, 15-60. 
De Lauretis, Teresa

1984 Alicia doesn't: feminism, semiotics, cinema. Bloomington: Indiana University Press.

DE Man, Paul

[1984] 1991 "La autobiografía como desfiguración". Revista Anthropos, 29, 113-118.

Feierstein, Daniel

2007 El genocidio como práctica social. Entre el nazismo y la experiencia argentina. Buenos Aires: FCE.

Feierstein, Daniel

2009 "Guerra, genocidio, violencia política y sistema concentracionario en América Latina”. En Terrorismo de estado y genocidio en América Latina. Comp., Daniel Feierstein. Buenos Aires: Prometeo, 9-32.

Feld, Claudia

2002 Del estrado a la pantalla: las imágenes del juicio a los ex comandantes en Argentina. Madrid - Buenos Aires: Siglo XXI.

Franco, Marina

2008 El exilio. Argentinos en Francia durante la dictadura. Buenos Aires: Siglo XXI.

FRIEDLÄNDER, Saul (comp. y pról.)

2007 En torno a los límites de la representación. El nazismo y la solución final. Bernal: Universidad Nacional de Quilmes.

Gamerro, Carlos

2015 "Memoria sin recuerdos". En Facundo o Martín Fierro. Los libros que inventaron la Argentina. Buenos Aires: Sudamericana, 489-523.

García, Victoria

2012 "Testimonio literario latinoamericano. Una reconsideración histórica del género". Ex Libris. 1, 371-389.

JaRA, René y Hernán VidAL

1986 Testimonio y literatura. Minneapolis: Institute for the Study of Ideology and Literature. 
LACAPRA, Domick

[2001] 2005 Escribir la historia, escribir el trauma. Trad., E. Marengo. Buenos Aires: Nueva Visión.

LABOv, William y Joshua WALETZKY

1967 "Narrative analysis: Oral versions of personal experience”. En Essays on the verbal an usual acts. Eds., J. Helms. Seattle: University of Washington Press, 12-44.

LABOV, William

[1972] 1984 Modelos sociolingüísticos. Madrid: Cátedra.

Lejeune, Philippe

1975 El pacto autobiográfico y otros estudios. Trad., A. Torrent. Pról., P. J. Eakin. Paris: Seuil.

Levi, Primo

[1947] Si esto es un hombre. Trad., P. Gómez Bedate. Buenos Aires: 2015a Ariel.

Levi, Primo

[1963] La tregua. Trad., P. Gómez Bedate. Buenos Aires: Ariel. $2015 b$

Levi, Primo

[1986] 2011 Los hundidos y los salvados. Trad., P. Gómez Bedate. Barcelona: Océano.

LUDMER, Josefina

2012 Aquí América Latina. Una especulación. Buenos Aires: Eterna Cadencia.

Martínez, Matías y Michael Scheffel

2011 Introducción a la narratología. Buenos Aires: Las cuarenta.

Mestman, Mariano

2008 "Raros e inéditos del Grupo Cine Liberación. A 40 años de La hora de los hornos". Sociedad. 27.

Molloy, Sylvia

[1996] 2001 Acto de presencia. La escritura autobiográfica en Hispamérica. México: Fondo de Cultura Económica. 
Nofal, Rossana

2002 La escritura testimonial en América Latina. Imaginarios revolucionarios del sur. Tucumán: Instituto Interdisciplinario de Estudios Latinoamérica, Facultad de Filosofía y Letras, UNT.

Peña, Fernando Martín y Carlos Vallina

2000 El Cine Quema: Raymundo Gleyzer. Buenos Aires: Ediciones De la Flor.

PRIVIDERA, Nicolás

2014 Elpaís del cine. Para una historia política del nuevo cine argentino. Buenos Aires: Los Ríos.

Ricoeur, Paul

2004 "El testigo". En La memoria, la historia, el olvido. Trad., A. Neira. Buenos Aires: FCE, 208-236.

SARLO, Beatriz

2005 Tiempo pasado. Cultura de la memoria y giro subjetivo. Una discusión. Buenos Aires: Siglo XXI.

TOPUZian, Marcelo

2003 "Paul de Man ¿la imposibilidad de la autobiografía?”. Anclajes. VII. 7, 255-275.

URONDO, Francisco

[1967] 2014 “Carta abierta”. En Del otro lado 1960-1965. En Obra poética. Buenos Aires: Adriana Hidalgo.

URONDO, Francisco

[1973] 2011 La patria fusilada. Buenos Aires: Libros del náufrago.

WaLSH, Rodolfo

[1957] 1984 Operación masacre. Buenos Aires: Ediciones de la Flor.

WALSH, Rodolfo

[1969] 2004 ¿Quién mató a Rosendo? Buenos Aires: Ediciones de la Flor.

WaLSH, Rodolfo

[1973] "Hoy es imposible en la Argentina hacer literatura desvinculada 1994a de la política”. Entrevista de Ricardo Piglia a Rodolfo Walsh, marzo de 1970. En Rodolfo Walsh, vivo. Comp. y pról., Roberto Baschetti. Buenos Aires: Ediciones de la Flor, 62-74. 
WALSH, Rodolfo

[1973] 2012 Caso Satanowsky. Buenos Aires: Ediciones de la Flor.

WALSH, Rodolfo

[1976] "Carta a Vicky", "Carta a mis amigos”. En Rodolfo Walsh, vivo.

1994b Comp. y pról., Roberto Baschetti. Buenos Aires: Ediciones de la Flor, 186-191.

WALSH, Rodolfo

[1995] 2010 Ese hombre y otros papeles personales. Ed. y pról., Daniel Link. Buenos Aires: Ediciones de la Flor.

Wieviorka, Annette

[1998] 2006 The Era of The Witness. Nueva York: Cornell University Press Ithaca.

Recepción: 17/09/2019

Aceptación: 13/10/2020 